\title{
Water Processing for Isotope Recovery Using Porous Zero Valent Iron
}

\author{
George Larsen*1, Simona E. Hunyadi Murph ${ }^{1,2}$, Kaitlin Coopersmith ${ }^{1}$, and Lucas Mitchell ${ }^{1}$ \\ ${ }^{1}$ National Security Directorate, Savannah River National Laboratory, Aiken, SC USA \\ ${ }^{2}$ Department of Physics and Astronomy, The University of Georgia, Athens, GA, USA \\ *Corresponding author - Address: Savannah River National Laboratory, Savannah River Site, \\ Bldg 999-2W, Aiken, SC 29808; Email: george.larsen@srnl.doe.gov; Fax: 803-725-2021
}

Number of Pages: 21; Number of Tables: 1; Number of Figures: 5 (Color, Online Only)

\begin{abstract}
Reduction-oxidation cycles of metals can be harnessed to create a reusable tritiated water processing system. The concept is straightforward; a tritium-contaminated steam passes over a hot metal bed, converting the metal to a metal oxide and liberating hydrogen isotopes for further processing and isotope separation. The bed is regenerated by converting the metal oxide back to a bare metal using protium gas, creating a clean water stream. Free oxygen is not produced during the cyclical process, making it safe for use in a hydrogen processing facility, and the only by-product is detritiated water. Porous zero valent iron (p-ZVI) has been identified as an ideal candidate material for this process due to its low cost, unique morphology and favorable thermodynamics. Therefore, investigations of p-ZVI were conducted to better understand how a bed composed of such material would behave in a tritium processing facility. The thermal and physical properties were assessed, along with cycling and isotope effects. The results indicate that p-ZVI beds could serve as a low cost, reusable system for the treatment of water in tritium processing facilities.
\end{abstract}

Keywords: Tritium processing, water splitting, hydrogen, deuterium 


\section{Introduction}

Tritium is a radioactive isotope of hydrogen, and like the other isotopes of hydrogen, it readily diffuses through materials [1]. Radioactive tritium can also negatively impact the humans and biota if large volumes are released in the environment. Thus, tritium handling requires careful manipulation as it could potentially lead to significant detrimental impacts on public health [2]. Tritiated water requires additional consideration since it easily forms in the atmosphere via isotopic exchange and is also easily absorbed by the human body [3]. The formation of tritiated water in a tritium processing facility is unavoidable and often intentional as a means of air detritiation [4]. The tritiated water that accumulates in a tritium facility must be processed to recover tritium and reduce emissions. The Tritium Facility at Savannah River Site (SRS) offers a representative example. All process equipment in the Tritium Facility are located within nitrogen gloveboxes, which provide containment for any tritium that may escape during processing. Any tritium that migrates to these gloveboxes is captured for recovery by continually recirculating the glovebox atmosphere through tritium stripper systems [5]. These stripper systems work by combusting tritium with ambient oxygen to form tritiated water, which is subsequently collected on molecular sieve beds. The ITER Detritiation System follows a similar process, where final detritiation of process gases and enclosure atmospheres is accomplished through the oxidation of tritium to water [6].

For relatively low levels of tritium, Combined Electrolysis and Catalytic Exchange process (CECE) is the preferred method for water detritiation [7]. For higher levels of tritium activity, a common process is to use hot metal beds, typically uranium or magnesium, to crack tritiated water, capturing the oxygen as a metal oxide and releasing hydrogen isotopes for further processing $[8,9]$. At SRS, tritiated water vapor is processed through a bed of hot magnesium 
metal mixed with stainless steel springs [10]. Due to the thermodynamic properties of magnesium, these beds, known as mag beds, are single use. Once the magnesium metal is converted to magnesium oxide, the bed must be replaced. The spent mag beds, along with the trapped oxygen, exit the process as tritiated metal-oxide which is then disposed as low-level waste. While this process is safe and reliable, a reusable metal bed system is desirable to reduce the costs and efforts associated with mag bed replacement and disposal.

Iron can be used to crack tritiated water into its respective hydrogen isotopes and decompose other impurities [8, 11-13]. Notably, after iron has been oxidized to iron oxide, the iron oxide can subsequently be regenerated back to iron using hydrogen, creating a reusable system. In this case, the water splitting and regeneration steps are performed at different temperatures and/or different hydrogen/water partial pressures. In addition to optimal thermodynamics for water splitting and regeneration, iron/iron oxide has a number of other ideal properties for a reusable tritiated water splitting process, including wide availability, chemical stability, and non-toxicity. Other materials with favorable thermodynamics do not exhibit these traits. For example, tin/tin oxide and carbon/carbon dioxide have comparable thermodynamic properties but form a corrosive liquid metal (tin) and a gas $\left(\mathrm{CO}_{2}\right)$ upon reduction and oxidation, respectively. Thus, iron may be considered the ideal bulk material for reversible water splitting.

Iron-based materials such as porous, micro, and nanoscale materials, are particularly attractive for water splitting applications due to their large surface areas, which leads to improved kinetics. Zero valent iron (ZVI) has received significant attention as a source for permeable reactive barriers for groundwater remediation $[14,15]$. It is also economically available in porous (p-ZVI) forms that provide additional surface areas for reactions. The properties of p-ZVI (e.g., 
low cost, non-toxic, favorable thermodynamics) are appealing for the cyclical treatment of tritiated water vapor, but it has not been investigated for this process, even though it is an ideal candidate.

This report provides an experimental investigation of a cyclical reduction and oxidation process using p-ZVI for tritiated water handling. The thermal and physical properties of p-ZVI were assessed, along with cycling and isotope effects in order to better understand how a bed composed of such material would behave in a processing facility. The results demonstrate that the material could serve as the basis for a reusable highly tritiated water processing system.

\section{Experimental}

\subsection{Materials}

The porous zero-valent iron was obtained from Höganäs Environmental Solutions Reference materials for thermal measurements, Sn (99.999\%), Zn (99.999\%), and In (99.99\%), were obtained from Alfa-Aesar. Deuterium oxide (99.8 atomic \%) was obtained from Sigma-Aldrich.

\subsection{Water Splitting and Regeneration Testing}

Water splitting and regeneration testing was conducted using a Micromeritics AutoChem II 2920 automated catalyst characterization system. The water splitting capacity of p-ZVI was tested at different reduction temperatures $500-800{ }^{\circ} \mathrm{C}$ under flowing $2.9 \% \mathrm{H}_{2}$ in $\mathrm{Ar}$ or $100 \% \mathrm{H}_{2}$ [50 standard cubic centimeters per minute (sccm)], followed by water splitting at $500{ }^{\circ} \mathrm{C}$, with saturated water vapor carried in Ar gas (50 sccm), where the saturation temperature (21, 50, 70, or $90{ }^{\circ} \mathrm{C}$ ) varied depending on the experiment. The hydrogen and water isotopes were monitored using a MKS Cirrus 2 quadrupole mass spectrometer. The water splitting/ reduction was run until the $\mathrm{H}_{2} \mathrm{O}$ and $\mathrm{H}_{2} / \mathrm{D}_{2}$ signals approached feed levels, indicating the p-ZVI was fully oxidized/reduced. 


\subsection{Particle Morphology}

Scanning electron microscopy (SEM) imaging was performed on Hitachi TM3000 TableTop SEM. Samples were adhered to the sample stage using double sided carbon tape. Images were acquired with $15 \mathrm{kV}$ acceleration voltage. Image analysis was performed using ImageJ software, where the sizes were obtained based on the feret distances on particles that were intact and not overlapping. The reported average lengths are calculated from 90-100 particles per sample. Surface porosity was obtained by measuring the percentage of pixels in an area of the image that was thresholded to the pores.

\subsection{Thermal Conductivity Measurements}

Thermal conductivity analyses were conducted using a Shimadzu DTG-60 simultaneous DTA-TG apparatus under an Ar purge of 40 sccm. Porous zero-valent iron was placed in an alumina crucible and a metal bead (Zn, Sn, and In) was placed in the center of the iron. The samples were loaded into the furnace and purged at room temperature under Ar overnight to prevent oxidation of the metal. Heating cycles were carried out two times at $10^{\circ} \mathrm{C} / \mathrm{min}$ to $485^{\circ} \mathrm{C}$ for zinc samples, $285^{\circ} \mathrm{C}$ for tin samples and $180{ }^{\circ} \mathrm{C}$ for indium samples. Heat flow calibrations were carried out from 30$485{ }^{\circ} \mathrm{C}$ at $10{ }^{\circ} \mathrm{C} / \mathrm{min}$ with a sapphire standard in equation 1 based on the technique described in ASTM E1269-11.

$$
\text { Power }=\frac{c m \beta}{D T A_{\text {sapphire }}-D T A_{\text {crucible }}}
$$

Where $c$ is the specific heat capacity $\left(\mathrm{J} \cdot{ }^{\circ} \mathrm{C} / \mathrm{g}\right)$ of sapphire from ASTM ET269-11, $m$ is the mass of the sapphire (g), $\beta$ is the heating rate $\left({ }^{\circ} \mathrm{C} / \mathrm{s}\right)$, and $D T A_{\text {sapphire }}$ and $D T A_{\text {crucible }}$ are the heating curves for the sapphire and crucible, respectively. 
The slope of the DTA curves at the linear region in the thermogram corresponds to the melting point of the metal, where the temperature is assumed constant. Therefore, the total thermal resistance, $R$, $\left(R=R_{D T A}+R_{\text {sample }}\right)$ is equal to the inverse of the slope, as shown in equation 2:

$$
\text { slope }=\frac{1}{R_{D T A}+R_{\text {sample }}}
$$

Where $R_{D T A}$ and $R_{\text {sample }}$ are the thermal resistances with and without the metal.

The thermal conductivity, $\kappa$, was calculated from the slope and the geometry of the pan, as shown in equation 3 :

$$
\kappa=\frac{1}{2 \pi R}\left(\frac{1}{r_{\text {metal }}}-\frac{1}{r_{\text {crucible }}}\right) B
$$

where

$$
\begin{aligned}
& r_{\text {metal }}=\text { radius of the metal } \\
& r_{\text {crucible }}=\text { radius of crucible } \\
& B=\text { correction factor from reference }[16] \text { based on } \\
& \text { the height and diameter of the pan, } H \text { and } D_{p} \text {, } \\
& \text { respectively }\left(H / D_{p}\right) \text { and the ratio of metal to } \\
& \text { pan diameters. }
\end{aligned}
$$

\subsection{Pressure Measurements}

A custom-built manifold and packed bed consisting of 0.25-in. outer diameter tubing, a mass flow controller (Alicat - P-100PSIG-D), and a differential pressure sensor (Omega - custom differential pressure transducer, 0 - 20 Torr) was assembled for pressure drop analysis. The differential pressure transducer compared the regions before and after the incorporation of p-ZVI bed. The pressure drop was measured by flowing argon across two different bed heights: $1 / 3$ packed $(0.13 \mathrm{~m}$ height) and fully packed (0.305 $\mathrm{m}$ height). Differential pressure values were measured from $\Delta P=$ 
0 - 20 Torr in flow rate increments of 2-5 sccm, where initial values were allowed to equilibrate before the equilibration pressure drop was obtained.

\subsection{Isotope Cross Contamination}

Isotope cross-contamination measurements were conducted using the Micromeritics AutoChem II 2920 automated catalyst characterization system. The water reservoir used to generate the water vapor was filled with deionized water and spiked with $\mathrm{D}_{2} \mathrm{O}$, resulting in a final deuterium concentration of $0.82 \%$ deuterium. The deuterium concentration was determined using a Los Gatos Research TIWA-45-EP water isotope analyzer. Argon was bubbled through the water reservoir at $50 \mathrm{sccm}$ at $21^{\circ} \mathrm{C}$ and passed over the p-ZVI for one hour. Then $\mathrm{H}_{2}$ was passed over the p-ZVI for one hour. The water generated during the regeneration was collected in a dry ice trap and analyzed for deuterium concentration.

\section{Results and Discussion}

\subsection{Water Splitting Tests}

The water splitting capacity of p-ZVI was investigated at different reduction temperatures 500 $800{ }^{\circ} \mathrm{C}$ under flowing $2.9 \% \mathrm{H}_{2}$ in $\mathrm{Ar}$, followed by water splitting at $500{ }^{\circ} \mathrm{C}$, with saturated water vapor at $90{ }^{\circ} \mathrm{C}$ carried in Ar gas. The results are shown in Figure 1a. The $\mathrm{H}_{2}$ production amount is not a monotonic function of the reduction temperature, which is likely due to cycling induced changes in p-ZVI properties, such as surface area. Therefore, the cyclical stability of the water splitting process using p-ZVI was also investigated. Repeated cycles were performed at the same conditions: reduction at $700{ }^{\circ} \mathrm{C}$ under flowing $2.9 \% \mathrm{H}_{2}$ in $\mathrm{Ar}$, followed by water splitting at 500 ${ }^{\circ} \mathrm{C}$, with saturated water vapor at $90^{\circ} \mathrm{C}$ carried in Ar gas. As shown in Figure 1b, the initial water splitting capacity is large and rapidly settles into a stable value after 2 cycles. The stability from 
2-10 cycles is encouraging from a process implementation standpoint. However, the amount of hydrogen generated per gram of p-ZVI is rather low. Specifically, $0.005 \mathrm{~L}_{\text {of }} \mathrm{H}_{2}$ per g of p-ZVI corresponds to the reversible oxidation of $\mathrm{Fe} \rightarrow \mathrm{FeO}_{0.012}$. The efficiency of the process needs to be improved, otherwise p-ZVI beds will be too large to be practically implemented.

One way to improve the water splitting efficiency is to increase the amount of iron oxide that is reduced to iron in the p-ZVI particles during the regeneration step. This can be achieved by increasing the concentration of $\mathrm{H}_{2}$ gas during reduction from $2.9 \%$ to $100 \%$, since this will have the same effect as reducing the relative oxygen partial pressure [17]. Thus, cyclical water splitting experiments similar to the ones described above were performed, except in this case the p-ZVI was reduced in $100 \% \mathrm{H}_{2}$ gas prior to water introduction. The results from these experimental runs are presented in Figure 2. The non-monotonic behavior observed again here is due to cycling induced changes to the p-ZVI properties. Notably, the water splitting capacity for the p-ZVI increases by more than an order of magnitude when pure $\mathrm{H}_{2}$ gas is used for the reduction/regeneration step. The production of $0.09 \mathrm{~L}$ of $\mathrm{H}_{2}$ per g of p-ZVI corresponds to the reversible oxidation of $\mathrm{Fe} \leftrightarrow \mathrm{FeO}_{0.22}$. Therefore, an $80 \mathrm{~kg}$ p-ZVI bed could process 50,000 L at standard temperature and pressure (STP) of $\mathrm{H}_{2} \mathrm{O}$ a year if the bed was regenerated once per month, assuming a long term $\mathrm{H}_{2}$ production capacity of $50 \mathrm{~mL} / \mathrm{g}$. $80 \mathrm{~kg}$ of p-ZVI occupies a volume of about $1.2 \mathrm{ft}^{3}$, which is a reasonable size for process equipment. This increased water splitting capacity and compact size allows for the relatively easy incorporation of p-ZVI beds into an industrial facility. .

\subsection{Morphology and Cyclic Stability}

The water splitting capacity of p-ZVI is stable over $10+$ cycles for $2.9 \% \mathrm{H}_{2}$ reduction cycles. For the $100 \% \mathrm{H}_{2}$ reduction cycles, the water splitting capacity remained stable for over 20 cycles, after 
an initial decrease, from around $80 \mathrm{~mL} / \mathrm{g}$ to around $60 \mathrm{~mL} / \mathrm{g}$, which could be attributed to morphological changes in the material. Therefore, scanning electron microscopy (SEM) imaging was conducted to observe if any physical changes to the p-ZVI particles occurred during cyclical water splitting. Figure 3 shows micrographs of the surface of p-ZVI particles at increasing magnification, both before and after 20+ water splitting cycles. As can be seen in the images, the surface became smoother with smaller pores appearing after cycling. Image processing software was used to measure the \% area of the pores and statistical analysis of particle sizes in the SEM images before and after cycling. The pristine p-ZVI surface has an $18 \%$ surface porosity, while the cycled p-ZVI has a 9\% surface porosity. The average pore size decreased from $2.7 \mu \mathrm{m}$ to 0.4 $\mu \mathrm{m}$ after cycling. These assessments indicate that the pores are decreasing in size and density after repeated water splitting cycles. In addition to pore sizes, the overall particle morphology changes as well. There is a general decrease in average particle size after cycling. The results from this statistical analysis are shown in Figure 4. Notably, the longest and shortest sides of the irregularly shaped particles decrease by an average of $200 \mu \mathrm{m}$, from $700 \mu \mathrm{m}$ to $500 \mu \mathrm{m}$ and from $500 \mu \mathrm{m}$ to $300 \mu \mathrm{m}$, respectively.

Reduction in particle size is not unexpected and is common for materials that are cycled at higher temperatures in hydrogen environments [18]. Similarly, the sintering of the porous surface is also commonly observed in materials used for thermochemical water splitting [19]. As described above, these morphological changes affect the initial changes seen in the water splitting cycles but do not appear to significantly affect the long-term water splitting capacity of the p-ZVI. These morphological changes, however, can impact the thermal and gas flow properties of the bed.

\subsection{Thermal Conductivity}


While isothermal cycles are possible, the results have shown that greater efficiencies are achieved when the regeneration and water splitting steps are done at different temperatures. Therefore, the thermal properties of p-ZVI are important parameters because these will help determine how fast these heating and cooling cycles can occur. In particular, the thermal conductivity, $\kappa$, of p-ZVI will determine the rate of conductive heat transfer through the bed.

The measured thermal conductivity of p-ZVI at different calibration temperatures are presented in Table I. The measured thermal conductivity of the p-ZVI range from $\kappa=0.071$ $\mathrm{W} / \mathrm{m} \cdot \mathrm{K}$ at $156.59{ }^{\circ} \mathrm{C}$ to $\kappa=0.054 \mathrm{~W} / \mathrm{m} \cdot \mathrm{K}$ at $419.59{ }^{\circ} \mathrm{C}$. The result generated when Sn was used as a reference measurement is presented in Table I, but this $\kappa$ value is questionable, as it appeared that Sn alloyed with the Fe surface and affected the experiment. It is important to note that the experiments were conducted in an Ar atmosphere and that the samples were pristine, uncycled pZVI. The thermal conductivity of a packed, porous bed will depend on background gas, so the $\kappa$ values will be higher in $\mathrm{N}_{2}$ or $\mathrm{H}_{2}$ atmospheres. Also, the thermal conductivity may change as the morphology and porosity of the p-ZVI particles change with cycling. The decrease in surface

porosity will promote a higher thermal conductivity, while the decrease in particle size will tend to decrease thermal conductivity.

\subsection{Pressure Drop}

The pressure drop across a packed bed containing materials of interest is an important gas processing parameter. Gas will not flow through a loop if the pressure drop is too large for the system's pump or blower. The pressure drop for a packed bed reactor can be calculated through the Ergun equation in the general case [20]. For laminar flows, the simpler Kozeny-Carman equation can be used:

$$
\frac{\Delta P}{L}=-\frac{180 \mu}{\theta^{2} D_{P}^{2}} \frac{(1-\epsilon)^{2}}{\epsilon^{2}} u_{s},
$$


where $\Delta P=$ pressure drop; $L=$ length of the bed, $\mu=$ fluid viscosity, $\theta=$ sphericity of the particles, $\epsilon=$ porosity of the bed, $D_{p}=$ particle diameter, $u_{s}=$ superficial velocity of gas. Thus, if the bed and particle geometries are known, the pressure drop for any system can be calculated.

To confirm that a packed p-ZVI bed obeyed the Kozeny-Carman equation, the pressure drop across a packed p-ZVI bed were measured using a differential pressure sensor at different gas velocities, $u_{s}$. The results are presented in Figure 5. The pressure drop as calculated by the Kozeny-Carman equation is also shown, where $\theta=0.0119$ and $D_{p}=0.698 \mathrm{~mm}$ (both measured using ImageJ). The porosity value of $\epsilon=0.5$ was selected as this gave the best visual fit for both bed lengths. Using these values, the pressure drop across a p-ZVI bed can be calculated for all laminar flows and bed sizes. In general, it can be expected that the pressure drop across a p-ZVI bed is less than 200 torr per meter for superficial gas velocities below $100 \mathrm{~m} / \mathrm{s}$.

\subsection{Decontamination Factor}

Most of the previous discussion has focused on the water splitting properties of p-ZVI, but an equally important component of the p-ZVI process is the regeneration cycle. In this case, the clean water produced during the hydrogen reduction of p-ZVI must be sufficiently clean for disposal. That is, little to no cross-contamination from the cracked tritiated water into the water produced during regeneration cycle should be detected.

Experiments were performed to measure any cross-contamination between water splitting and regeneration cycles. Specifically, a $\mathrm{D}_{2} \mathrm{O}-\mathrm{H}_{2} \mathrm{O}$ mixture $\left(8200 \mathrm{ppm} \mathrm{D}_{2} \mathrm{O}\right)$ was passed over a reduced p-ZVI sample for 60 minutes at $500{ }^{\circ} \mathrm{C}$. Then, the sample was heated to $600{ }^{\circ} \mathrm{C}$ and regenerated for the same amount of time in hydrogen gas. During the regeneration cycle, the product gases were routed through a cold trap to collect the water produced by the reduction of pZVI. This cold trap was bypassed during the water splitting experiments. The water collected 
during regeneration was analyzed using cavity ring down spectroscopy to measure the concentrations of hydrogen isotopes. For these experiments, a decontamination factor (DF) was calculated, where the DF is equal to the ratio of the concentration of $\mathrm{D}_{2} \mathrm{O}$ in the water splitting cycle to the concentration of $\mathrm{D}_{2} \mathrm{O}$ recovered in the cold trap during the regeneration cycle. The DF for the p-ZVI water splitting process was found to be DF > 134 .

The measured p-ZVI DF value reported here is based on initial bench-scale experiments, so there is further room for optimization. First, the size of p-ZVI sample was much smaller than the wetted components of experimental system during DF testing, so it is highly probable that most of the residual $\mathrm{D}_{2} \mathrm{O}$ seen in the regeneration stream came from other components and piping and not from the p-ZVI, especially from regions that were at much lower temperatures than the reactor section. The DF factor is expected to be higher in larger scale systems, where the reactor size is much larger than the shared manifolds. Prototype systems that do not use shared piping will also see higher DFs. Also, the water splitting and regeneration cycles were run back to back in the experiment. Evacuating the reactor or providing some isotopic swamping in between cycles will further increase the DF [12]. It should also be noted that the hydrogen used in these experiments contains small amounts of deuterium, which leads to a lower DF than would be measured for tritium. Tritium uptake due to water corrosion of $\alpha$-Fe has been observed at lower temperatures [21]. The process is delayed by oxide formation in iron [21], but tritium migration into the metal is one possible mechanism for limitations on achievable DF, depending on how much is absorbed at the oxidation temperature and how much is releasable at the regeneration temperature [22].

However, it is worth noting that this initial DF value is already much greater than those reported for commercial catalytic exchange columns ( DF = 25 - 35) currently used for detritiation and approaches detritiation targets for cooling water at Tennessee Valley Authority Watts Bar (DF 
= 140) [23]. With further optimization, the single stage DF could be improved to higher values. Final implementation within a tritium processing facility will depend on emissions targets. Costbenefit analyses against other detritiation processes are needed for commercial applications, but the advantages of implementing regenerable p-ZVI beds in a detritiation process over using other techniques include low cost materials (Fe vs. Pt), hydrogen recycling, simplicity (no electrolyte or permeable membrane), safety (no oxygen stream), lower energy (vs. combined electrolysis catalytic exchange), and the ability to handle high activity water.

\subsection{Conclusions}

The research presented above investigates the reduction-oxidation cycles of porous zero valent iron and evaluates whether such a process could be harnessed to create a reusable water processing system for highly tritiated water. The thermal and physical properties of the material have been assessed, along with cycling and isotope effects. The major findings are: 1) The long-term cycling behavior of porous zero valent iron are found to be stable even after 20 cycles at temperatures over $500{ }^{\circ} \mathrm{C}$. 2) An initial decontamination factor of $\mathrm{DF}>134$ is found for the reusable porous iron process, which exceeds commercial processes. Notably, the system has plenty of room for further optimization of the decontamination factor. 3) The measured thermal, physical, and isotopic properties of porous zero valent iron demonstrate that the material could serve as the basis for a low cost, reusable highly tritiated water processing system.

Acknowledgments. This manuscript has been authorized by Savannah River Nuclear Solutions, LLC under contract No. DE-AC09-08SR22470 with the US Department of Energy. The United States Government retains and the publisher, by accepting this article for publication, 
acknowledges that the United States Government retains a non-exclusive, paid-up, irrevocable, worldwide license to publish or reproduce the published form of this work, or allow others to do so, for United States Government purposes. Financial support for this work was provided by the SRS Plant Directed Research, Development and Demonstration (PDRD) program. The authors gratefully acknowledge of Paul Korinko, Dien Li, Steve Xiao, Tim Worrell, Davis Cyr, Heather Mentzer, and Summer Schaufler for their assistance with this project.

\section{References}

1. Perujo, A. and K.S. Forcey, Tritium permeation barriers for fusion technology. Fusion Engineering and Design, 1995. 28: p. 252-257.

2. Taylor, N., et al., Materials-related issues in the safety and licensing of nuclear fusion facilities. Nuclear Fusion, 2017. 57(9): p. 092003.

3. Okada, S. and N. Momoshima, Overview of tritium: characteristics, sources, and problems. Health physics, 1993. 65(6): p. 595-609.

4. Wu, Q., et al., Preparation of Multifunctional Detritiation Catalyst and Design of Detritiation Reactor in Fusion Facility. Fusion Science and Technology, 2018. 73(1): p. 50-58.

5. Heung, L.K. and M.L. Rhoden, Performance of a Large-Scale Glovebox-Stripper System. Fusion Science and Technology, 2002. 41(3P2): p. 583-587.

6. Beloglazov, S., et al., Configuration and operation of detritiation systems for ITER Tokamak Complex. Fusion Engineering and Design, 2010. 85(7): p. 1670-1674.

7. Boniface, H.A., et al., Water Detritiation System for ITER-Evaluation of Design Parameters. Fusion Science and Technology, 2017. 71(3): p. 241-245.

8. Heinze, S., P. Bussiere, and T. Pelletier, French experience in tritiated water management. Fusion Engineering and Design, 2003. 69(1): p. 67-70.

9. Willms, R.S., S. Konishi, and K. Okuno, Use of Magnesium for Recovering Hydrogen Isotopes from Tritiated Water. Fusion Technology, 1994. 26(3P2): p. 659-663. 
10. Heung, L., et al., Tritium confinement in a new tritium processing facility at the Savannah River Site. Fusion Technology, 1992. 21(2P2): p. 594-598.

11. Modica, G. and R.A.H. Edwards, A Reactor-Permeator for Reduction of Tritium Oxide on Iron. Fusion Technology, 1995. 27(2T): p. 75-78.

12. Edwards, R.A.H. and G. Modica, Reduction of Tritiated Water on a Regenerable Iron Reactant: Pilot Plant Design. Fusion Technology, 1995. 28(3P1): p. 586-590.

13. James, D.W. and G.A. Morgan, Evaluation of getters for methane and ammonia decomposition. Fusion Engineering and Design, 2018. 133: p. 1-5.

14. Wang, C.-B. and W.-X. Zhang, Synthesizing nanoscale iron particles for rapid and complete dechlorination of TCE and PCBs. Environmental science \& technology, 1997. 31(7): p. 2154-2156.

15. Crane, R.A. and T.B. Scott, Nanoscale zero-valent iron: Future prospects for an emerging water treatment technology. Journal of Hazardous Materials, 2012. 211-212: p. 112-125.

16. Pujula, M., et al., Measuring Thermal Conductivity of Powders with Differential Scanning Calorimetry: A Simplified Method. J. Therm. Anal. Calorim., 2016. 125: p. 571-577.

17. Shaw, H.R., Hydrogen-Water Vapor Mixtures: Control of Hydrothermal Atmospheres by Hydrogen Osmosis. Science, 1963. 139(3560): p. 1220-1222.

18. Eliaz, N., D. Eliezer, and D. Olson, Hydrogen-assisted processing of materials. Materials Science and Engineering: A, 2000. 289(1-2): p. 41-53.

19. Roeb, M., et al., Materials-Related Aspects of Thermochemical Water and Carbon Dioxide Splitting: A Review. Materials, 2012. 5(11): p. 2015-2054.

20. Ergun, S. and A.A. Orning, Fluid flow through randomly packed columns and fluidized beds. Industrial \& Engineering Chemistry, 1949. 41(6): p. 1179-1184.

21. Otsuka, T. and K. Hashizume, Behavior of Tritium Permeation Induced by Water Corrosion of Alpha Iron around Room Temperature. Fusion Science and Technology, 2015. 67(3): p. 511-514.

22. Hashizume, K. and T. Tanabe, Electromigration of Tritium in V-4Cr-4Ti. Fusion Science and Technology, 2011. 60(3): p. 1135-1138.

23. Brooks, K., G. Sevigny, and E. Love. Review and Evaluation of Water Detritiation Technologies for Watts Bar Primary Cooling Water. in Tritium Focus Group Meeting. 2017. Pacific Northwest National Laboratory, Richland, WA. 
Tables

Table I. Thermal Conductivity Measurements

\begin{tabular}{|c|c|c||}
\hline Material & $\begin{array}{c}\text { Temperature } \\
\left({ }^{\circ} \mathbf{C}\right)\end{array}$ & $\begin{array}{c}\text { Thermal Conductivity } \\
(\mathbf{W} / \mathbf{m} \cdot \mathbf{K})\end{array}$ \\
\hline $\mathrm{p}-\mathrm{ZVI}+\mathrm{In}$ & 156.59 & 0.071 \\
\hline $\mathrm{p}-\mathrm{ZVI}+\mathrm{Sn}$ & 231.95 & 0.021 \\
\hline $\mathrm{p}-\mathrm{ZVI}+\mathrm{Zn}$ & 419.59 & 0.054 \\
\hline
\end{tabular}


Figures
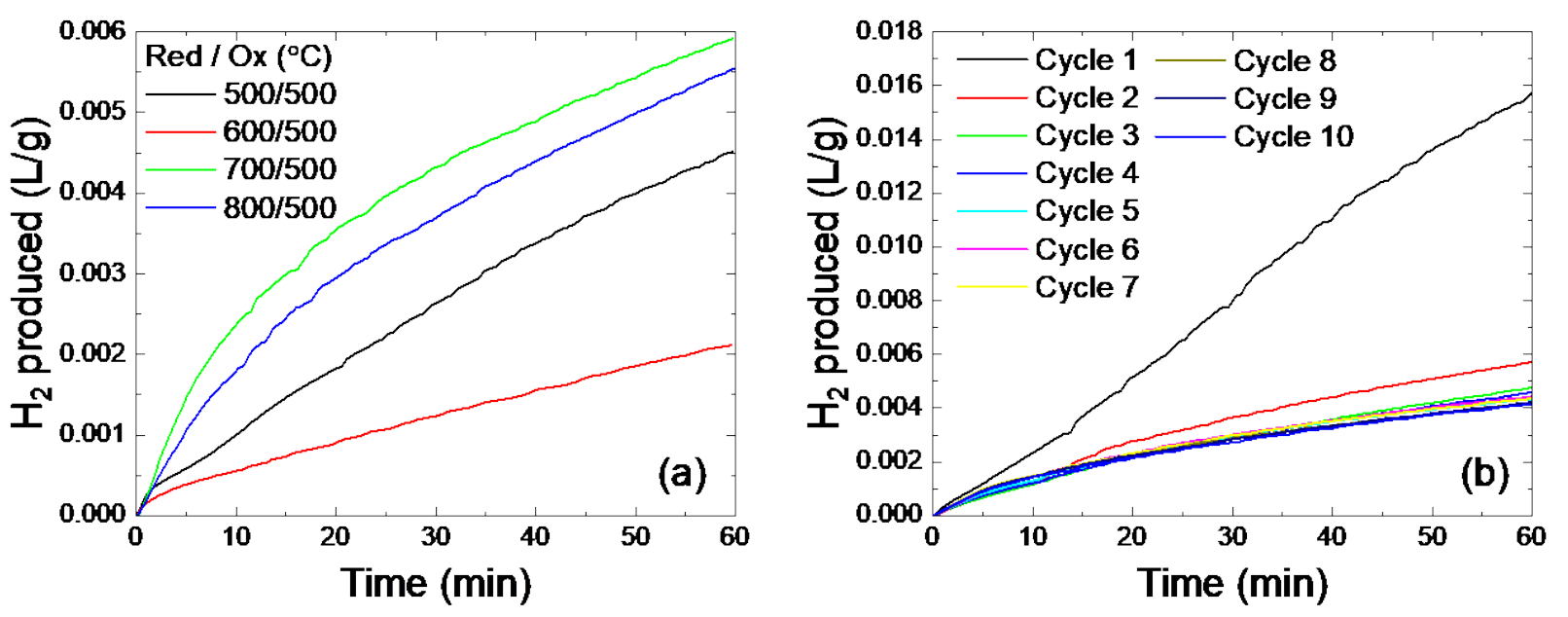

Figure 1. (a) Water splitting and (b) cyclical stability testing of p-ZVI 


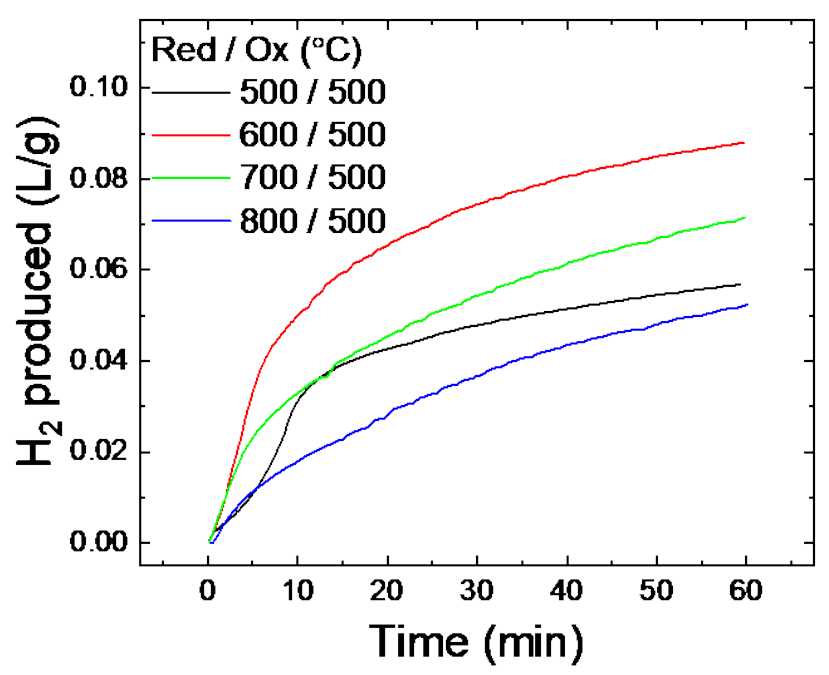

Figure 2. Water splitting testing of p-ZVI using $100 \% \mathrm{H}_{2}$ gas during the regeneration/reduction step 

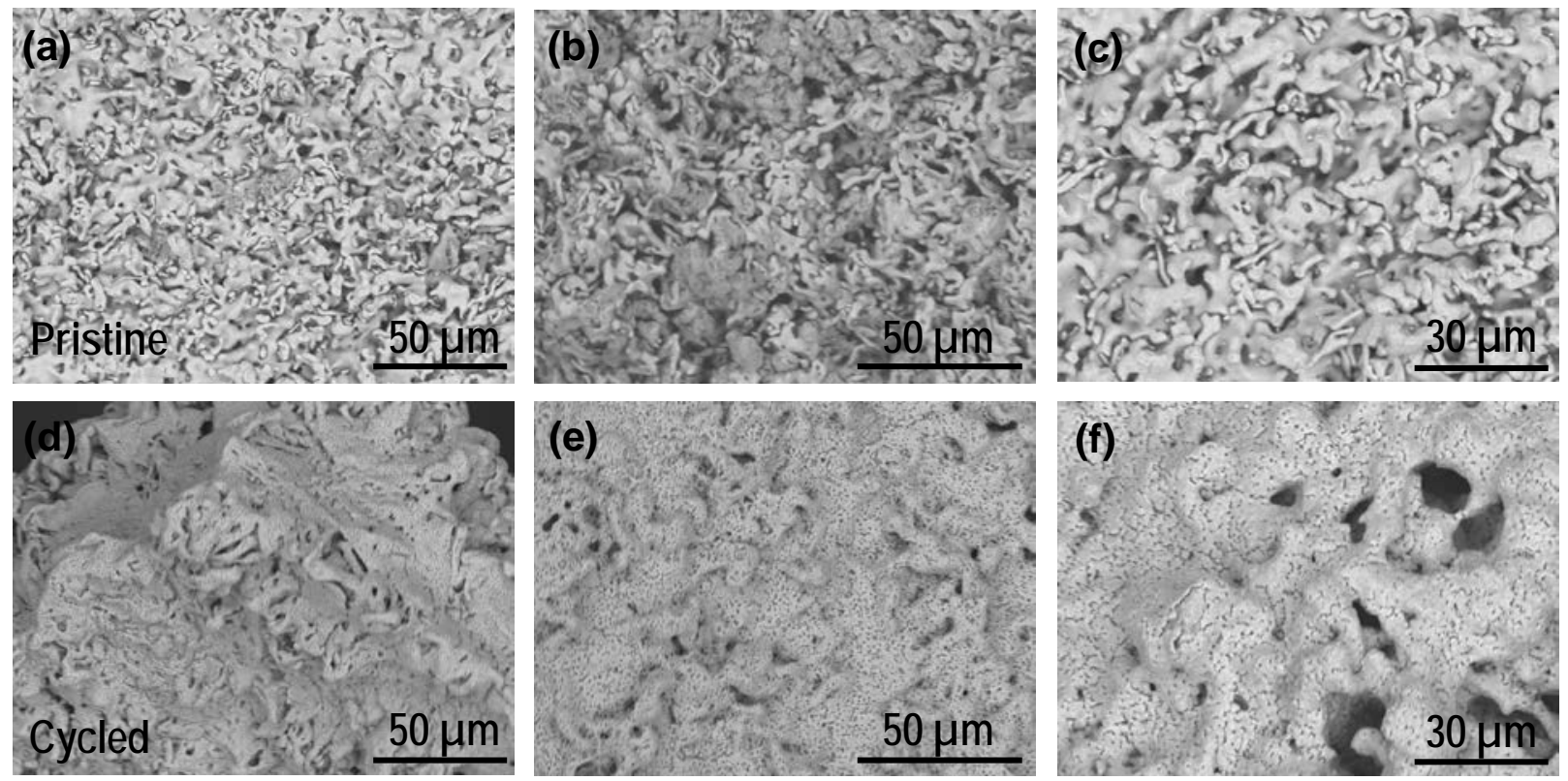

Figure 3. SEM images of the (a) - (c) pristine and (d) - (f) cycled p-ZVI particle surfaces at $1200 \times, 1500 \times$, and $2000 \times$ magnifications, respectively. 

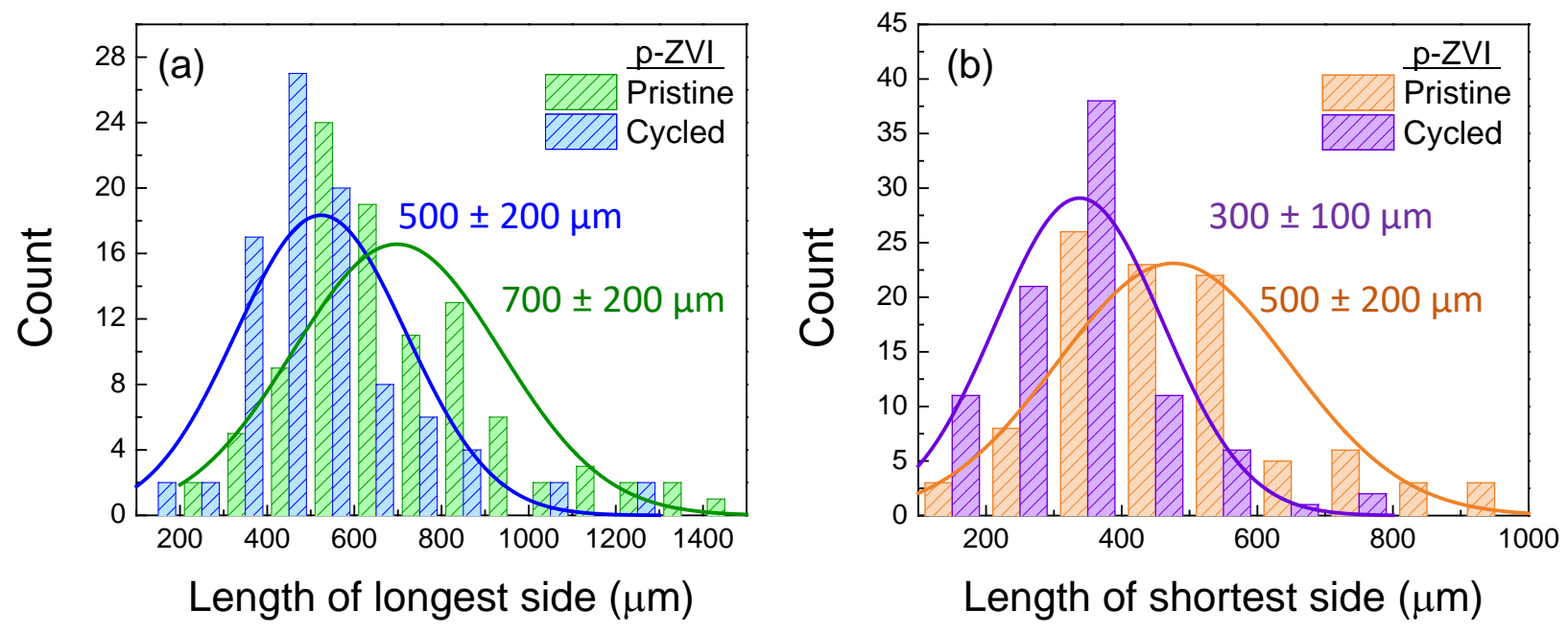

Figure 4. Results of the image statistical analyses showing the particle counts and the lengths for the (a) longest and (b) shortest sides. 


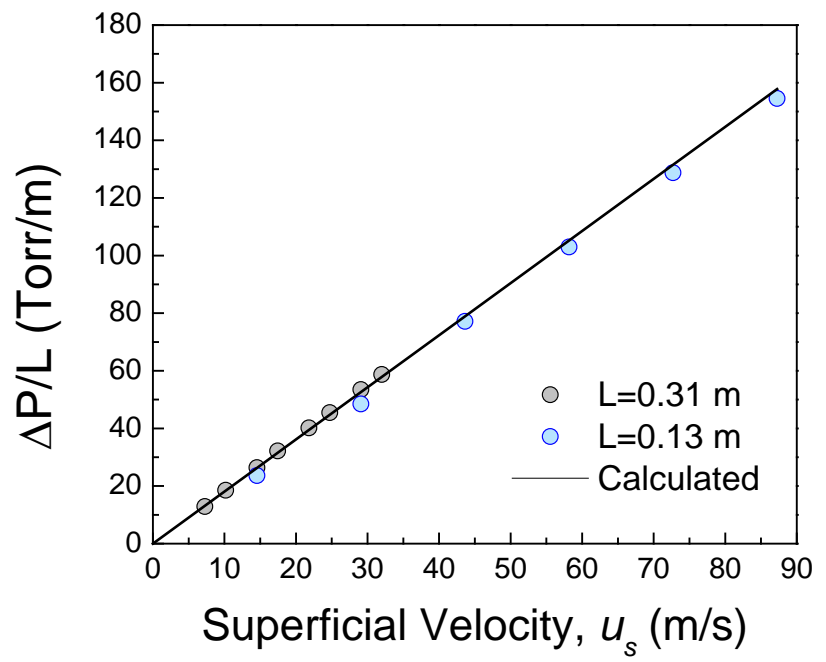

Figure 5. Measured and calculated pressure drop versus superficial velocity for p-ZVI beds with two different lengths. 